RU Содержание обучения моряков иноязычной письменной коммуникации в компетентностной парадигме

\author{
Молева М. В.
}

\begin{abstract}
Аннотация. Цель исследования - разработать содержание обучения работников морского транспорта иноязычной письменной коммуникации, опираясь на положения и понятийный аппарат компетентностного подхода. Научная новизна исследования заключается в разработке и систематизации содержательных основ обучения работников водного транспорта письменной коммуникации на иностранном языке в компетентностной парадигме. В результате исследования разработано содержание обучения кадров морского флота, представленное в виде трех компонентов: социолингвистического, психологического и дидактико-методического. Содержание обучения разработано в соответствии с целями обучения, представленными в компетентностной форме.
\end{abstract}

\title{
EN Teaching Written Foreign-Language Communication to Maritime Transport Workers on the Basis of Competence-Based Approach
}

\author{
Moleva M. V.
}

\begin{abstract}
The research objective is as follows: relying on provisions and conceptual apparatus of a competence-based approach, the author develops the content of teaching written foreign-language communication to maritime transport workers. Scientific originality of the study involves developing conceptual foundations of teaching written foreign-language communication to maritime transport workers on the basis of competence-based approach. The research findings are as follows: the author reveals the structure of maritime workers' written foreign-language competence, which includes sociolinguistic, psychological and didactical-methodological components. Educational content is developed regarding foreign language competence requirements for maritime workers.
\end{abstract}

\section{Введение}

Актуальность темы исследования обусловлена необходимостью разработки содержания обучения кадров морского транспорта письменной деловой коммуникации на иностранном языке с опорой на положения компетентностного подхода. Компетентностная парадигма предполагает выполнение требований по достижению коммуникативного и профессионального успеха в ходе делового общения на иностранном языке. Содержание обучения, согласно выводам современной методической науки, служит реализации цели обучения и рассматривается как то, чему следует научить обучающихся в образовательном процессе. В компетентностной парадигме целью обучения иностранному языку или его аспекту стало формирование иноязычной коммуникативной компетенции. В федеральных государственных образовательных стандартах последнего поколения в вузах, осуществляющих подготовку кадров морского флота, понятие «компетенция» также соотносится с целевым компонентом обучения. Целью иноязычной подготовки работника морского транспорта в сфере деловой письменной коммуникации на иностранном языке является формирование ряда компонентов иноязычной коммуникативной компетенции (субкомпетенций), позволяющих успешно осуществлять иноязычную профессиональную коммуникацию. Реализуясь в процессе формирования иноязычных профессиональных субкомпетенций, содержание обучения способствует достижению различных аспектов цели обучения. В настоящей статье представлено содержание обучения работников морского флота иноязычной деловой письменной коммуникации, систематизированное в соответствии с формируемыми в процессе обучения субкомпетенциями как искомым результатом обучения. 
Для достижения указанной цели исследования необходимо решить следующие задачи: 1) уточнить цель обучения работников морского транспорта иноязычной письменной коммуникации в компетентностной парадигме; 2) определить структуру и компонентный состав содержания обучения письменной коммуникации на иностранном языке кадров морского флота; 3) разработать и систематизировать содержание обучения работников морского транспорта с учетом формируемых субкомпетенций.

В статье применяются такие методы исследования, как лингвистический, психологический, дидактический, системный анализ, обобщение, синтетические методы.

Основной теоретической базой исследования послужили труды ученых, разрабатывающих и уточняющих положения компетентностного подхода и содержание компетенций, входящих в состав иноязычной коммуникативной компетенции. Настоящее исследование основано на изучении работ С. Л. Буковского, Н. Д. Гальсковой, М. Н. Горанской, А. Г. Горбунова, Э. Ф. Зеера, И. А. Зимней, П. Ю. Золотова, А. А. Колесникова, Е. Г. Таревой, В. Ф. Тенищевой, А. Н. Шамова, А. Н. Щукина и др.

Практическая значимость исследования заключается в применении основных идей научного исследования в системе упражнений для повышения эффективности формирования умений деловой письменной иноязычной речи в морском вузе. Материалы предлагаемого исследования могут быть применены на лекциях по методике преподавания иностранных языков в педагогических вузах; вопросы, затронутые в настоящем исследовании, могут использоваться для обсуждения на семинарских занятиях со студентами педагогических вузов, вебинарах и круглых столах, посвященных проблемам языкового образования в неязыковых вузах. Материалы настоящего исследования могут быть учтены при разработке компетентностных методических пособий и учебников для студентов вузов водного транспорта.

\section{Основная часть}

\section{Цель обучения работников морского транспорта иноязычной письменной коммуникации в компетентностной парадигме}

В методике обучения иностранным языкам категория цели является ведущей, поскольку задает общее направление обучения. Ученые указывают на зависимость цели обучения иностранному языку от социального заказа общества по подготовке специалистов различных профессиональных сфер (Гальскова, Василевич, Акимова, 2017; Шамов, 2017; Зимняя, 2012).

Компетентностная образовательная парадигма, положенная в основу современных федеральных государственных образовательных стандартов нового поколения (ФГОС ВО 3++), продиктовала направленность обучения на достижение практико-ориентированного результата (Вербицкий, 2004; Ермаков, 2011; 3еер, 2005; Зимняя, 2012). По словам авторов С. В. Дорфман и Е. В. Ермолаевой (2020), компетентностный подход преодолевает конфликт теоретической и практической подготовки обучающихся, приближая процесс обучения кадров морского флота к миру реальной профессиональной деятельности.

В свете новой компетентностной парадигмы стремление к овладению иностранным языком как средством общения с учетом социокультурных особенностей партнера по коммуникации определило цель обучения как формирование у обучающихся иноязычной коммуникативной компетенции. Состав иноязычной коммуникативной компетенции достаточно динамичен и, по словам А. А. Колесникова (2019), подвергается постоянному обновлению и усложнению для решения задач «эффективного взаимодействия в современной социальной среде».

Основной целью обучения работников морского транспорта в сфере иноязычной письменной коммуникации является овладение деловой письменной речью на иностранном (английском) языке в пределах определенных жанров и типов текстов, составляющих основной корпус судового дискурса. С позиций компетентностного подхода цель обучения определяется как формирование у обучающихся на морских специальностях иноязычной профессиональной письменно-речевой компетенции (ИППРК).

Изучение корпуса судовой документации как определенного типа дискурса позволило отметить следующие его особенности: 1) лингвистической основой судового письменного дискурса выступает морская, деловая и правовая терминология (лексическая составляющая) и определенный набор грамматических конструкций, принятых в англоязычной деловой письменной коммуникации (Молева, 2020); 2) судовой письменный дискурс осуществляется в международном пространстве в условиях взаимодействия представителей разных культур; 3) коммуникативное поле судового письменного дискурса ограничено решением задач профессиональной деятельности; 4) судовой письменный дискурс регламентируется правилами международной деловой коммуникации.

Анализ особенностей судового письменного дискурса позволил автору прийти к заключению, что в состав ИППРК как цели обучения моряков письменной коммуникации на иностранном языке необходимо включить две группы субкомпетенций, отражающих подлежащие освоению умения: профессионально-коммуникативные умения и культурно-деловые умения. Профессионально-коммуникативные умения развиваются при формировании языковой, речевой, личностно-социальной, стратегической и дискурсивной субкомпетенций. Культурноделовыми умениями обучающиеся овладевают при формировании у них социокультурной и прагматической субкомпетенций (Молева, 2019a; 2019b).

Языковая, или лингвистическая, компетенция в предлагаемых условиях обучения предусматривает способность к пониманию и продуцированию в письменной форме бесконечного множества предложений, грамотно построенных в языковом отношении при помощи языковых знаков и правил их соединения на всех уровнях языка, включая орфографический, лексический, грамматический и синтаксический (Азимов, Щукин, 2009). 
Речевая компетенция базируется на освоении обучающимися способов формулирования и выражения мысли в ходе иноязычного общения с учетом норм, узуса и традиций изучаемого языка (Щукин, 2008). Речевая компетенция, реализуемая в ходе профессиональной деятельности, согласно исследованию В. Ф. Тенищевой (2008), подразделяется на предметно-речевую и контекстно-речевую компетенции.

Большинство ученых сходится во мнении, что неотъемлемым компонентом коммуникативной компетенции выступает социальная компетенция, в целом понимаемая как потребность в отношениях с другими людьми. В условиях профессиональной коммуникации происходит взаимодействие членов единого коллектива или группы (экипажа) в ходе решения бытовых и служебных задач. Взаимодействие с коллегами подразумевает как удовлетворение собственной потребности в общении или получении необходимой производственной информации, так и уверенную личную и профессиональную позицию, заслуживающую уважение со стороны других сотрудников. В этой связи мы считаем уместным использование термина личностносоциальная компетенция как компонента ИППРК.

Исследования последних лет широко рассматривают вопросы формирования стратегической, или компенсаторной, компетенции как необходимого компонента в составе коммуникативной компетенции. В основе стратегической компетенции лежит понятие «стратегия», суть которого заключается в наличии у говорящего (пишущего) плана речевых действий и поступков, в активизации доступных обучающемуся языковых средств и социокультурных знаний в ходе иноязычного речевого общения для осуществления и поддержания процесса коммуникации (Михайлина, 2017; Татарина, 2019; Тарева, Сергеева, 2019). Компенсаторная компетенция акцентирует внимание на формировании у обучающихся способности к компенсации недостатка ресурсов (языковых, речевых, социокультурных, опыта иноязычного общения и т.д.), препятствующих успешной коммуникации (Горанская, 2009; Тарева, Сергеева, 2019). Несмотря на различие понятий, формирование как стратегической, так и компенсаторной компетенций преследует одни и те же цели: развить у обучающихся способность к полноценной коммуникации при недостаточности языковых и речевых средств, дефиците опыта общения на иностранном языке, незнании этикетных норм речевого поведения и др. (Азимов, Щукин, 2009; Шамов, 2020). Профессор А. Н. Шамов (2020) отмечает тесную взаимосвязь лингвистической и стратегической компетенций. У обучающегося должны быть сформированы умения строить адекватное ситуации общения высказывание, пользуясь имеющимися у него в арсенале языковыми средствами.

Следующим необходимым, на наш взгляд, компонентом ИППРК, которым необходимо овладеть работникам морского транспорта, выступает дискурсивная компетенция. Дискурсивная компетенция определяется в современной методической литературе как способность понимать и создавать различные виды коммуникативных высказываний, характеризующихся целостностью, логичностью, связностью в различных речевых регистрах и функциональных стилях, с выбором речевых средств, реализующих коммуникативную интенцию говорящего (пишущего) и соответствующих ситуации общения (Горбунов, 2013; Дорохов, 2008; Погосян, 2011).

Профессиональная деятельность кадров морского флота происходит в условиях социального и культурного взаимодействия в составе многонационального экипажа судна и с различными службами в иностранных портах и в море. Вот почему мы считаем необходимым формирование у кадров морского флота социокультурной компетенции как компонента ИППРК. Как отмечают И. И. Костылев и М. К. Овсянников (2015), отсутствие сформированной социокультурной компетенции у моряков приводит к сбоям в профессиональном общении на судне из-за культурных разногласий между членами экипажа. Последствия таких нарушений могут оказаться трагичными. Другой аспект культурно-делового общения профессиональной деятельности моряков требует, по словам О. Г. Полякова (2007), «прагматической осведомленности» участников коммуникации. Деловая переписка и другие виды иноязычных письменных высказываний судового дискурса основаны на прагматических речевых действиях, а именно: запросить определенную информацию, приказать или настойчиво просить осуществить какое-либо необходимое действие, отказаться от совершения действия, подтвердить факты и т.д. (Маслова, 2010). Использование таких речевых действий подразумевает воздействие на партнера по коммуникации для достижения определенной практической цели (Овчинникова, Колотова, 2017). Речевое воздействие отражает прагматический аспект профессионально-ориентированной коммуникативной деятельности человека (Маслова, 2010). Соответственно, следующим компонентом ИППРК, подлежащим формированию у кадров морского транспорта, выступает прагматическая компетенция. Современные исследователи определяют прагматическую компетенцию следующим образом: 1) способность успешно донести смысл высказывания до адресата с учетом социокультурного фона и ситуации общения (Золотов, 2020); 2) владение системой средств и приемов воздействия на собеседника, обеспечивающих успешное коммуникативное взаимодействие (Овчинникова, Колотова, 2017); 3) правильно с точки зрения норм иностранного языка использовать лингвистические средства для достижения поставленных целей коммуникации, учитывая ряд факторов профессиональной коммуникации, таких как ситуация общения, контекст деятельности и задачи профессионального общения (Драбкина, 2001).

Таким образом, цель обучения работников морского транспорта иноязычной письменной коммуникации в компетентностной парадигме может рассматриваться как формирование ряда субкомпетенций, составляющих иноязычной профессиональной письменно-речевой компетенции (ИППРК). Параллельное формирование указанных субкомпетенций направлено на обеспечение успешности деловой письменной коммуникации и вызывает профессиональный интерес обучающихся к изучению иностранного языка. 
Структура и компонентный состав содержания

обучения письменной коммуникации на иностранном языке кадров морского флота

Содержание обучения рассматривается как базовая историческая категория в методике преподавания иностранных языков (Щукин, 2008). Ученые-методисты единодушны в определении содержания обучения иностранному языку как «совокупности того, что обучающийся должен освоить в процессе обучения» (Азимов, Щукин, 2009; Гальскова, Василевич, Акимова, 2017; Буковский, Щукин, 2020). Вместе с тем вопрос о структуре и компонентном составе содержания обучения до сих пор не решен однозначно.

В настоящем исследовании мы будем опираться на структуру и компонентный состав содержания обучения, предлагаемый учеными М. А. Ариян и А. Н. Шамовым (2017). Ученые выделяют три компонента содержания обучения письму и письменной речи: лингвистический (языковые знания), психологический (речевые навыки и умения) и дидактико-методический (формирование специальных учебных навыков и умений по организации самостоятельной работы обучающихся над иноязычным учебным материалом).

Как мы выяснили в ходе исследования, успешность профессиональной коммуникации обеспечивается, помимо владения языковой системой, способностью создавать иноязычное письменное высказывание определенного жанра, используя уместные речевые средства (дискурсивная компетенция), вступать в письменную коммуникацию, невзирая на ограниченный запас иноязычных коммуникативных ресурсов (стратегическая компетенция), воздействовать на партнера по общению, добиваясь намеченных коммуникативных и практических целей в ходе письменного иноязычного общения (прагматическая компетенция), проявлять положительное отношение к реалиям иноязычной деловой культуры (социокультурная компетенция). Вот почему для целей нашего исследования, направленного на обучение деловой письменной коммуникации, лингвистический компонент обучения целесообразно обозначить как социолингвистический компонент и дополнить его рядом субкомпонентов: дискурсивным, стратегическим, прагматическим, социокультурным.

Таким образом, содержание обучения кадров морского транспорта деловой иноязычной письменной коммуникации состоит их трех компонентов, находящихся в линейной взаимосвязи: социолингвистического, психологического, дидактико-методического. Социолингвистический компонент включает дискурсивный, стратегический, прагматический и социокультурный субкомпоненты.

В психологический компонент содержания обучения включаются профессионально-направленные коммуникативные навыки и умения, позволяющие участнику коммуникации достигнуть практических целей в ходе письменного делового общения.

В дидактико-методический компонент содержания обучения включены навыки, умения, способности и деловые качества обучающегося, развиваемые во время самостоятельной работы по освоению письменной коммуникации на иностранном языке в пределах судового дискурса.

\section{Содержание обучения моряков с учетом формируемых субкомпетенций}

1. Социолингвистический компонент содержания обучения

Выделенный нами социолингвистический компонент содержания обучения работников морского транспорта иноязычной письменной деловой коммуникации базируется на различных видах знаний обучающихся, необходимых для успешной профессиональной коммуникации. К таким званиям мы отнесли непосредственно языковые и социальные знания, дискурсивные знания, стратегические знания, прагматические знания и социокультурные знания.

На орфографическом уровне лингвистические знания включают: 1) знания графической системы изучаемого языка; 2) знания правил орфографии английского языка; на лексическом уровне обучающиеся овладевают знаниями: 1) общеупотребительной лексики, соответствующей бытовой сфере общения; 2) общеморских терминологических единиц; 3) специальных морских терминологических единиц; 4) общеделовых лексических единиц; 5) специальной деловой лексики (Юршева, 2001); 6) специальных аббревиатур и акронимов морского подъязыка и их полной формы; 7) специальной правовой лексики. Примерами таких специальных лексических единиц могут служить: charterer - «фрахтователь» (общеморская, общеделовая лексика), deadfreight - «плата за зафрахтованное, но не использованное место на судне» (специальная деловая лексика), flat «понтон, баржа» (специальная морская лексика), FIOS (free in and out and stowed) - судно не оплачивает расходы по погрузке, выгрузке, укладке груза (акроним, соответствующий специальной деловой и морской терминологии) (Бобровский, 1979).

Грамматический уровень, включая синтаксис, подразумевает следующие обязательные знания: 1) способов построения простых и сложных предложений английского языка; 2) порядка слов в английском предложении; 3) видовременных форм английского языка действительного и страдательного залога; 4) знание эллиптических конструкций морского подъязыка; 5) инфинитивных конструкций; 6) герундия и причастных оборотов; 7) пассивных конструкций.

Успех коммуникации зависит от личностной и социальной позиции будущего профессионала, его способности строить и контролировать свое речевое поведение в процессе деловой коммуникации. На наш взгляд, обучающимся на морских специальностях следует овладеть следующими знаниями: 1) речевых действий, отражающих расположенность работника морского транспорта к положительному речевому взаимодействию в письменной форме с другими сотрудниками (членами команды, членами экипажа другого судна, судовыми агентами, чиновниками порта, пассажирами и др.); 2) правил письменного речевого поведения, направленных на развитие отношений сотрудничества с другими людьми; 3) письменных речевых средств, 
отражающих положительную самооценку и чувство собственного достоинства пишущего; 4) речевого этикета иноязычного письменного общения; 5) формул социального этикета (просьба, извинение, отказ и т.д.).

Таким образом, для формирования личностно-социальной компетенции в содержание обучения включаются знания, направляющие внимание обучающихся на основные формы корректного социального поведения, находящего отражение в языковых и речевых средствах деловой переписки. Выбор речевых средств в этом случае должен отражать как уважение к партнеру по переписке, так и самоуважение пишущего как представителя своей профессиональной сферы.

Для судового письменного дискурса наиболее характерными являются следующие жанры: 1) радиограммы (короткие сообщения, обычно передающие какую-либо срочную информацию); 2) формы (деловая информация по текущей работе, обычно представляемая по определенному шаблону); 3) коммерческая переписка; 4) коммерческие соглашения (договоры перевозки) (Бобин, 2017; Бобровский, 1979). Таким образом, знания, формируемые у обучающихся на морских специальностях для реализации дискурсивного субкомпонента социолингвистического компонента содержания обучения, включают: 1) основные формы судовой документации как типы текста и дискурса; 2) основные языковые и речевые особенности разных типов судового дискурса; 3) основные жанровые характеристики различных видов судовой документации. Дискурсивные и языковые знания находятся в тесной взаимосвязи. Например, студенты, усваивая способы составления радиограмм, обращают внимание на наличие значительного количества эллиптических конструкций, в то время как тексты договоров перевозок как другой тип судового дискурса требует максимально развернутых грамматических конструкций. В этом случае преподавателю следует обратить внимание обучающихся на зависимость выбора языковых и речевых средств от различий в коммуникативной цели данных видов письменных сообщений. В одном случае происходит передача срочной информации, в другом - фиксация коммерческой информации, затрагивающей финансовые интересы нескольких сторон. Вот почему текст радиограммы свернут, лаконичен, содержит строго фактическую информацию, а текст договора перевозки избыточен с речевой точки зрения.

Стратегический субкомпонент социолингвистического компонента обучения подразумевает трансляцию обучающимся знаний о возможности и необходимости вести деловую коммуникацию на иностранном языке при имеющемся запасе языковых и речевых средств. Стратегические знания на лексическом уровне включают: 1) синонимы общеупотребительных слов и выражений, общеморских и специальных морских терминов; 2) синонимы и синонимичные выражения делового английского языка; 3) синонимы и синонимичные выражения основных правовых терминов; 4) дефиниции, толкования основных морских, деловых и правовых терминов с целью замещения термина, ускользнувшего из памяти пишущего. На грамматическом уровне обучающиеся овладевают знаниями: 1) синонимичных грамматических конструкций для передачи похожей информации; 2) способов преобразования грамматических конструкций (активных в пассивные и наоборот, одного сложного предложения в несколько простых предложений и т.д.). При затруднениях, возникающих у студентов на орфографическом уровне, также полезны знания слов-синонимов, подходящих для передачи мыслей пишущего.

С целью формирования прагматической компетенции у обучающиеся в социолингвистический компонент содержания обучения нами включен прагматический субкомпонент. Данный субкомпонент содержания обучения реализуется при получении обучающимися на морских специальностях знаний: 1) набора языковых и речевых средств, принятых в деловых англоязычных текстах для решения определенной коммуникативной задачи; 2) способов вербализации коммуникативных интенций в сфере делового общения морской практики; 3) правил речевого поведения в типичных ситуациях профессионального общения, соответствующих социокультурному фону и гарантирующих успешную иноязычную коммуникацию; 4) основных тактик речевого поведения, обеспечивающих достижение коммуникативной и практической цели.

Для формирования социокультурной компетенции в деловом письменном общении на иностранном языке в содержание обучения будущих работников морского флота включаются знания: 1) социокультурных маркеров делового стиля судовой корреспонденции на английском языке; 2) формул вежливости; 3) речевых клишированных фраз как проявление уважительного отношения к партнеру по переписке; 4) социокультурных характеристик менталитета представителей морской сферы других стран.

Таким образом, мы рассмотрели социолингвистический компонент содержания обучения работников морского транспорта деловой письменной коммуникации на иностранном языке.

\section{2. Психологический компонент содержания обучения}

Следующим компонентом содержания обучения выступает психологический компонент, базирующийся на: 1) навыках и умениях письменной речи как вида речевой деятельности; 2) профессиональных деловых коммуникативных навыках и умениях.

Для формирования языковой компетенции в деловой письменной коммуникации на иностранном языке в содержание обучения включаются навыки и умения: 1) орфографически корректного написания наименований объектов морской практики; 2) грамотного и точного написания специальных терминов общеделовой и специальной деловой лексики, правовой лексики; 3) понимания и расшифровки специальных сокращений (аббревиатур) и акронимов, написание их полной формы.

С целью формирования речевой компетенции в психологический компонент содержания обучения включаются навыки и умения по усвоению обучающимися: 1) речевых образцов предметной сферы профессиональной деятельности, отобранных по принципу частотности; 2) узуальной стороны морской, деловой и правовой терминологии; 3) речевых клише, формул вежливости и устойчивых оборотов, традиционно используемых в деловой англоязычной корреспонденции; 4) контекстуального значения речевых единиц письменной деловой речи иноязычного судового дискурса. 
Формирование личностно-социальной компетенции требует включения в психологический компонент содержания обучения навыков и умений: 1) использования речевых тактик, способствующих продуктивной речевой коммуникации с партнерами по письменному общению; 2) совершения речевых поступков, отражающих способность пишущего ориентироваться в социальной и профессиональной ситуациях. Навыки и умения, необходимые обучающимся для формирования стратегической компетенции, заключаются в: 1) способности находить синонимичные слова и выражения для передачи собственных мыслей; 2) способности перестраивать предложение, меняя его структуру (Татарина, 2019); 3) переносе навыков и умений, отражающих профессиональный речевой опыт пишущего, из родного языка в изучаемый и наоборот (Горанская, 2009).

Формирование дискурсивной компетенции базируется на навыках: 1) использования специальных морских и юридических словарей и справочных пособий; 2) совершенствования графики, орфографии и каллиграфии английского языка; 3) совершенствования и соответствующего подбора языковых средств; 4) редактирования собственного текста и т.д. и умениях: 1) составлять целостное речевое произведение, обладающее признаками текста; 2) писать тексты радиограмм, требующих свертывания полных предложений до эллипсисов; 3) писать речевые произведения в соответствии с жанровыми особенностями основных судовых документов; 4) писать деловые письма, содержащие различные коммуникативные интенции (заказ, запрос, претензия, согласие, отказ и т.д.); 5) структурировать текст делового письма и договора и т.д.; 6) писать электронные сообщения в соответствии с их особенностями.

С целью формирования прагматической компетенции, обучающиеся овладевают навыками и умениями: 1) выбирать языковые и речевые средства, соответствующие ситуации общения, контексту деятельности, социокультурному фону; 2) пользоваться стратегиями и тактиками речевого поведения для достижения коммуникативной и профессиональной цели в конкретной ситуации общения; 3) перечитывать и корректировать собственный текст в случае допущенных языковых, речевых, социокультурных и профессиональных промахов.

Овладение работниками морского транспорта социокультурной компетенцией подразумевает навыки и умения: 1) налаживать контакт с новым адресатом, соблюдая правила делового речевого этикета при письменном иноязычном общении; 2) коротко и понятно описывать цель обращения к партнеру по коммуникации; 3) твердо придерживаться своей профессиональной позиции; 4) положительно принимать культурные отличия иноязычных партнеров по переписке; 5) проявлять чувство собственного достоинства как носителя культуры своей страны.

3. Дидактико-методический компонент содержания обучения

Дидактико-методический компонент обучения включает учебные навыки и умения по организации самостоятельной работы над учебным иноязычным материалом, а также подразумевает самостоятельное развитие способностей и деловых качеств по овладению профессиональной коммуникацией. С целью формирования языковой компетенции в деловой письменной речи на иностранном языке у обучающихся должны быть сформированы способности: 1) самостоятельно работать с новыми языковыми единицами, запоминать их значение, написание и правила их соединения с усвоенными ранее языковыми единицами; 2) целенаправленно пополнять словарный запас, включающий новые терминологические единицы морской, деловой и правовой сферы; 3) узнавать основные термины, имеющие международное значение, в текстах профессиональной направленности и передавать их на письме.

Формирование предметно-речевой и контекстно-речевой компетенций базируется на развитии у обучающихся способностей уметь самостоятельно: 1) формулировать и совершенствовать максимально точное выражение своих мыслей в письменной форме, связанных с ситуациями профессиональной деятельности; 2) осваивать алгоритмы типичных профессиональных речевых ситуаций письменного общения; 3) осуществлять мониторинг постоянно поступающей новой информации, связанной со сферами деятельности судна (операторской, технической, коммерческой и т.д.).

Для формирования личностно-социальной компетенции обучающиеся развивают способности и личностные качества: 1) устанавливать контакт с незнакомым адресатом в целях будущего сотрудничества или решения проблем, возникающих в ходе профессиональной деятельности; 2) поддерживать доброжелательные уважительные отношения с партнерами по профессиональной коммуникации; 3) проявлять настойчивость в достижении профессиональных целей, не оказывая выраженного давления на партнера по переписке; 4) отстаивать свою позицию в вопросах, касающихся собственных профессиональных и деловых интересов; 5) находить компромисс в спорных ситуациях, учитывать интересы другой стороны и др.

Способности и личностные качества обучающихся, требуемые для формирования стратегической компетенции, включают: 1) способность обучающегося; 2) способность преодолевать затруднения в коммуникации, возникающие вследствие дефицита языковых и речевых средств; 3) способность сосредоточиваться на предстоящем письменном высказывании на иностранном языке, осуществляя предварительный подбор необходимых языковых и речевых средств, имеющихся в запасе у обучающегося; 4) способность опираться на полученный ранее речевой опыт письменного общения.

Под способностями, развиваемыми при формировании дискурсивной компетенции, понимаются: 1) способность различать формы судовых документов по их жанровым характеристикам; 2) способность оценивать уместность языковых и речевых средств, их соответствие ситуации общения (Горбунов, 2013).

Иноязычная письменная коммуникация будет успешной, если в дидактико-методический компонент включены такие качества личности и способности, как: 1) непредвзятость по отношению к чужой культуре; 2) преодоление склонности к агрессии и конфликтному поведению на почве межкультурных разногласий. 
Способностями и личностными качествами, формирующими прагматическую компетенцию обучающихся, являются: 1) коммуникативная целеустремленность, то есть способность добиваться намеченных коммуникативных и практических целей в ходе письменного иноязычного общения; 2) внимательность к соответствию языковых и речевых средств ситуации общения, социокультурному контексту и профессиональной уместности; 3) гибкость в выборе стратегий и тактик речевого поведения; 4) способность учитывать индивидуальные характеристики адресата (социальный статус, должность, возраст и т.д.); 5) ответственность перед адресатом за собственное письменное высказывание.

\section{Заключение}

Таким образом, мы приходим к следующим выводам.

В ходе нашего исследования была поставлена и решена задача по уточнению цели обучения работников морского транспорта иноязычной деловой письменной коммуникации в компетентностной парадигме. Современный подход к обучению требует формулирования цели обучения в компетентностной форме. Для овладения умением вести деловую письменную коммуникацию на иностранном языке у обучающихся на морских специальностях должна быть сформирована ИППРК. Такая компетенция представляет собой искомую цель обучения. Изучение различных аспектов деловой письменной коммуникации морской практики определило ряд компонентов цели обучения, представленных в настоящем исследовании как компоненты ИППРК.

Уточненная цель обучения моряков иноязычной деловой письменной коммуникации определила содержание обучения. В настоящем исследовании структура содержания обучения представлена в виде трех взаимосвязанных компонентов: социолингвистического, психологического и дидактико-методического. Для достижения заданных целей обучения в социолингвистический компонент включаются дискурсивный, стратегический, прагматический и социокультурный субкомпоненты. Социолингвистический компонент содержания обучения включает различные виды знаний, необходимых обучающимся на морских специальностях для достижения целей обучения. Психологический компонент содержания обучения базируется на развитии у обучающихся различных видов профессионально-направленных коммуникативных навыков и умений. В дидактико-методический компонент нами включены способности и деловые качества, формируемые обучающимися самостоятельно в процессе обучения. Таким образом, задача по разработке и систематизации содержания обучения моряков иноязычной письменной коммуникации выполнена в ходе исследования.

Перспективы дальнейшего исследования проблемы мы видим в разработке: 1) подсистемы упражнений, направленных на формирование умений письменной деловой речи, реализующих содержание субкомпетенций иноязычной профессиональной письменно-речевой компетенции работников морского транспорта; 2) критериев сформированности искомых субкомпетенций; 3) специальных тестов для определения разных видов готовности к иноязычному общению.

\section{Источники | References}

1. Азимов Э. Г., Щукин А. Н. Новый словарь методических терминов и понятий (теория и практика обучения языкам). М.: ИКАР, 2009.

2. Ариян М. А., Шамов А. Н. Основы общей методики преподавания иностранных языков теоретические и практические аспекты: учебное пособие. М.: ФЛИНТА; Наука, 2017.

3. Бобин В. И. Терминологический справочник капитана по ведению дел и документации на английском языке. М.: ТРАНСЛИТ, 2017.

4. Бобровский В. И. Судовая документация и переписка на английском языке: учебное пособие. М.: ЦРИА «Морфлот», 1979.

5. Буковский С. Л., Щукин А. Н. Основы методики обучения иностранным языкам в схемах и таблицах. Иллюстративно-графический курс: учебное пособие. М.: ФЛИНТА, 2020.

6. Вербицкий А. А. Компетентностный подход и теория контекстного обучения: Материалы к четвертому заседанию методологического семинара (г. Москва, 16 ноября 2004 г.). М.: Исследовательский центр проблем качества подготовки специалистов, 2004. 84 с.

7. Гальскова Н. Д., Василевич А. П., Акимова Н. В. Методика обучения иностранным языкам: учебное пособие. Ростов-на-Дону: Феникс, 2017.

8. Горанская М. Н. Обучение будущих государственных служащих письменным формам профессиональноориентированного общения с опорой на иноязычную компенсаторную компетенцию // Вестник Костромского государственного университета им. Н. А. Некрасова. 2009. № 2.

9. Горбунов А. Г. К определению понятия «дискурсивная компетенция» // Вестник Ижевского государственного технического университета. 2013. № 4 (60).

10. Дорохов Р. С. Формирование прагматической компетенции студента-переводчика // Знание. Понимание. Умение. 2008. № 3.

11. Дорфман С. В., Ермолаева Е. В. Компетентностная модель подготовки выпускника водного транспорта по специальности «Судовождение» // Новые педагогические исследования: сборник статей II Международной научно-практической конференции (г. Пенза, 15 июня 2020 г.). Пенза: Наука и Просвещение, 2020.

12. Драбкина И. В. Прагмалингвистические аспекты письменного делового общения (на материале англоязычных текстов контрактов и деловой корреспонденции): дисс. ... к. филол. н. Самара, 2001. 
13. Ермаков Д. С. Компетентностный подход в образовании // Педагогика. 2011. № 4.

14. Зеер Э. Ф. Компетентностный подход к образованию // Образование и наука. Известия Уральского отделения Российской Академии Образования. 2005. № 3 (33).

15. Зимняя И. А. Компетенция и компетентность в контексте компетентностного подхода в образовании // Иностранные языки в школе. 2012. № 6.

16. Золотов П. Ю. Рассмотрение прагматической компетенции как структурного компонента иноязычной коммуникативной компетенции // Вестник Тамбовского университета. Серия: Гуманитарные науки. 2020. T. 25. № 184 .

17. Колесников А. А. Обучение иностранным языкам в свете новых компетентностных реалий // Иностранные языки в школе. 2019. № 5.

18. Костылев И. И., Овсянников М. К. Морское образование как пример международного сотрудничества // Высшее образование в России. 2015. № 6.

19. Маслова А. Ю. Введение в прагмалингвистику: учебное пособие. Изд-е 3-е. М.: ФЛИНТА; Наука, 2010.

20. Михайлина О. Н. Коммуникативные стратегии при формировании стратегической компетенции в иноязычной подготовке студентов // Азимут научных исследований: Педагогика и психология. 2017. Т. 6. № 2 (19).

21. Молева М. В. Специфика компонентного состава иноязычной письменной коммуникативной компетенции морских и речных специалистов // Современные научные исследования: актуальные проблемы и тенденции: сборник трудов Всероссийской научно-практической конференции «Речной Форум 2019» (г. Омск, 19-20 декабря 2019 г.) / сост. А. В. Степанов. Омск: ОИВТ (филиал) ФГБОУ ВО «СГУВТ», 2019а.

22. Молева М. В. Формирование иноязычной письменно-речевой компетенции у моряков // Великие реки-2019: Труды 21-го международного научно-промышленного форума (г. Нижний Новгород, 14-17 мая 2019 г.). Нижний Новгород: Волжский государственный университет водного транспорта, $2019 \mathrm{~b}$.

23. Молева М. В. Судовой письменный дискурс как средство профессиональной коммуникации работников водного транспорта // Научная дискуссия: вопросы филологии и методики преподавания иностранных языков: сборник статей по материалам Международной научно-практической конференции (г. Нижний Новгород, 02-03 апреля 2020 г.) / Мининский университет. Нижний Новгород: Нижегородский государственный педагогический университет имени Козьмы Минина, 2020.

24. Овчинникова М. В., Колотова Н. И. Формирование прагматической компетенции иностранных студентов на уроках РКИ как условие успешного коммуникативного взаимодействия // Ученые записки. Электронный научный журнал Курского государственного университета. 2017. № 2 (42).

25. Погосян В. А. Дискурсивная компетенция // Вестник Герценовского университета. 2011. № 12 (98).

26. Поляков О. Г. Методика развития прагматической осведомленности изучающих иностранный язык // Вестник Тамбовского государственного университета. 2007. Вып. 9 (53).

27. Тарева Е. Г., Сергеева М. Г. Специфика компенсаторной компетенции участника межкультурной коммуникации // Современный ученый. 2019. № 4.

28. Татарина Т. М. Развитие иноязычной стратегической компетенции у студентов неязыковых специальностей // Самарский научный вестник. 2019. Т. 8. № 3 (28).

29. Тенищева В. Ф. Интегративно-контекстная модель формирования профессиональной компетенции: автореф. ... дисс. д. пед. н. М., 2008.

30. Шамов А. Н. Методика обучения иностранным языкам: практикум Ростов-на-Дону: Феникс, 2017.

31. Шамов А. Н. Методика обучения иностранным языкам: Теоретический курс: учебное пособие. М.: ФЛИНТА, 2020.

32. Щукин А. Н. Лингводидактический энциклопедический словарь: более 2000 единиц. М.: Хранитель, 2008.

33. Юршева Л. А. Воспроизведение и речетворчество в английском языке делового общения: дисс. ... к. филол. н. М., 2001.

\section{Информация об авторах | Author information}

RU Молева Марина Валерьевна ${ }^{1}$

${ }^{1}$ Волжский государственный университет водного транспорта, г. Нижний Новгород; Нижегородское речное училище им. И. П. Кулибина

EN Moleva Marina Valer'evna ${ }^{1}$

${ }^{1}$ Volga State University of Water Transport, Nizhny Novgorod; Nizhny Novgorod River College named after I. P. Kulibin

${ }^{1}$ marina-moleva@yandex.ru

\section{Информация о статье | About this article}

Дата поступления рукописи (received): 05.05.2021; опубликовано (published): 28.12.2021.

Ключевые слова (keywords): компетентностный подход; иноязычная письменная коммуникация; иноязычная профессиональная письменно-речевая компетенция; судовой дискурс; профессионально-коммуникативные умения; competence-based approach; written foreign-language communication; professional oral and written foreign-language competence; shipping discourse; professional communicative competence. 